\title{
OPTICALLY STIMULATED LUMINESCENCE DATING OF COASTAL SEDIMENTS AT FUNING BAY, SOUTHEASTERN CHINA
}

\author{
JIANHUI JIN ${ }^{1,2}$, YUNMING HUANG ${ }^{3}$, ZHIZHONG LI ${ }^{1,2}$, XUECHUN FAN ${ }^{3}$, \\ ZHIYONG LING ${ }^{5}$, ZHIXING LI $^{4}$ and XIAOJU LIU ${ }^{4}$ \\ ${ }^{I}$ Institude of Geography, Fujian Normal University, Fuzhou, Fujian, China \\ ${ }^{2}$ Key Laboratory for Humid Subtropical Eco-geographical Processes of the Ministry of Education, Fujian Normal University, \\ Fuzhou, Fujian, China \\ ${ }^{3}$ Institude of Archaeology, Fujian Provincial Museum, Fuzhou, Fujian, China \\ ${ }^{4}$ School of Geographical Sciences, Fujian Normal University, Fuzhou, Fujian, China \\ ${ }^{5}$ Qinghai Institute of Salt Lakes, Chinese Academy of Sciences, Xi'ning, Qinghai, China
}

Received 29 June 2018

Accepted 6 November 2018

\begin{abstract}
The possible role of environmental change, especially sea level change, as a stimulus for the development of human residence and migration is poorly understood. We investigate this problem by showing a record of sea-level change and coastal transformation based on a sediment core (FN1 core) and a Neolithic site (Pingfengshan site) obtained from the Funing bay on the northeast coast of Fujian, China. The Funing bay coastal area represents a unique feature in China's Neolithic cultures, comprising a silty beach dominated by quartz-rich sand and several important sites of Huangguashan cultural period.

Samples from FN1 core and Pingfengshan site were taken for grain size ananlyses and for optically stimulated luminescence (OSL) dating. The blue-light stimulated OSL signals were measured by the single aliquot regenerative dose (SAR) protocol to determine the ages of of the samples. Samples from FN1 core yield OSL ages ranging from $49.9 \mathrm{ka}$ to $0.8 \mathrm{ka}$, providing the systematic geochronological evidence for the sea level change of Funing bay. The comparison of sea level change and Neolithic cultural periods presents a good relationship in coastal area of Fujian, China since about $7 \mathrm{ka}$ before present. In detail, the cultural types of Keqiutou culture and Huangguashan culture all belong to coastal mountainous culture, of which flourishing periods corresponds to the higher sea level periods of mid-late Holocene. Tanshishan culture belongs to estuarine coastal culture, and most sites of this period correspond to a lower sea level located at lower altitudes.
\end{abstract}

Keywords: optically stimulated luminescence (OSL), Neolithic culture, environmental change, Southeastern China.

\section{INTRODUCTION}

East coastal area of Fujian province, centring on the Funing bay, is a major concentrated area of Neolithic

Corresponding authors: J. Jin; Z. Li

e-mails: geojjh@fjnu.edu.cn; lizz@fjnu.edu.cn culture sites in the middle and lower reaches of Min River which is the longest river in Fujian province of China, with largest water and most extensive area. A large number of neolithic remains were found around this area. Those sites are the firsthand evidence for long-term use of marine resources and coastal environments in human evolution and subsequent development which is vital to understanding patterns of human subsistence (Nian, et al., 2015). In recent decades, several neolithic sites were 
discovered and excavated in Xiapu county, east coastal area of Fujian (Fujian provincial museum, 2017). Of particular significance is the Huangguashan Neolithic culture (4300-3500 cal BP) (Lin, 2012; Fan et al., 2014). For instance, Huangguashan site was discovered in 1987 and excavated in 1989 and 2002, respectively. Pingfengshan site, about $8 \mathrm{~km}$ from the Huangguashan site, was discovered in 2014 and excavated in 2016 (Fujian provincial museum, 2017). The above-mentioned sites show a similar cultural feature and were named Huangguashan culture by archaeologists. However, no older sites, such as Tanshishan culture sites (5000-4300 cal BP) and Keqiutou culture sites (6000-5500) which is the typical cultures in Taiwan Strait (Fujian and Taiwan), were discovered in this area so far. Is this phenomenon due to the human initiative migrations or regional resource and environment restriction? There is no final conclusion.

The modern topographic features of the research area are mainly showed by coastal plains, ocean bays and winding shorelines. And the palaeoenvironment changes of regions to the north and south of Fujian show a remarkable difference since the early Holocene which can influence the transformation of Neolithic archaeological sites in this area (e.g. Zong, 2004; Ma et al., 2016). Yet, although correlational studies of this area have made solid progress (e.g. Rolett et al., 2011), the highresolution studies of environmental change and Neolithic cultural response among the east coastal Fujian are completely lacking.

This study aims to fill the gap in our knowledge of the coupling relationship between regional environmental change and Neolithic cultural response of South China. The study in German North Sea coast of Zhang et al. (2014) shown that the optically stimulated luminescence (OSL) dating of quartz is a powerful tool for dating coastal sediments. In this paper, the OSL dating method was employed to quartz $(38-63 \mu \mathrm{m})$ in coastal sediments from the coast of Funing bay, Fujian China. Sea-level change can influence shifts in settlement pattern and elicit population movement in period of Neolithic cultural (Bailey and Flemming, 2008; Rolett et al., 2011; Jin et al., 2017a). Here we investigate the relationship between sea-level change and different civilisations in both sides of Taiwan Strait (Fujian and Taiwan) in combination with other relative research results, which is conductive to understanding the human-earth coupling relationship, such as environmental change and cultural response among coastal Fujian Neolithic cultures, the emergence of early systematic seafaring and the transmission routes of Austronesian languages.

\section{MATERIALS AND METHODS}

The Funing bay is a silty coast and located in Xiapu County, the east coastal area of Fujian province in southern China about $2 \mathrm{~km}$ far away from East China Sea rim (Fig. 1). We collected two cores from Funing bay (Table 1). The core FN1 and FN2 are located in intertidal zone and supratidal zone, respectively. The core FN1 (N26⒋ $\left.{ }^{\circ} 52.567^{\prime \prime}, \mathrm{E} 120^{\circ} 01^{\prime} 19.486^{\prime \prime}\right)$ was located about $2 \mathrm{~km}$ from the Pingfengshan Neolithic site (N26⒋ $\left.36.630^{\prime \prime}, \mathrm{E} 19^{\circ} 59^{\prime} 44.399^{\prime \prime}\right)$. The core FN1 is up to $15 \mathrm{~m}$ deep and contains a sediment record from around $55 \mathrm{ka}$ before present until the present. The top half $(0-7 \mathrm{~m})$ of the FN1 core have a continuous sediment record from around $7 \mathrm{ka}$ until the present. This time period spans the entire Neolithic era of the Fujian archaeological sequence.

Optically stimulated luminescence (OSL) dating of quartz has been used successfully and revolutionized since the early $2000 \mathrm{~s}$, and this technique can be applied to estimate depositional age of the sediments in different sedimentary environments (Aitken, 1998; Wintle and Murray, 2006). The core chronologies are based on 17 quartz-OSL age data of the sediments.

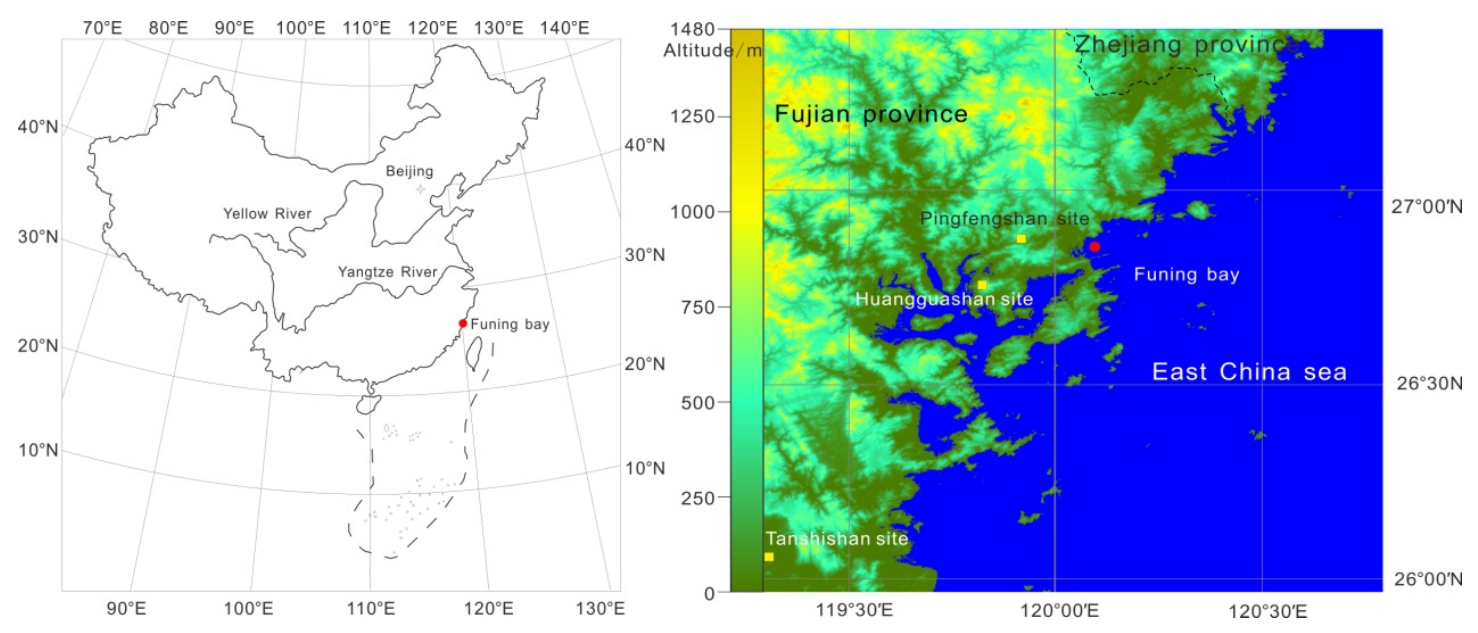

Fig. 1. Map showing the sampling location and the terrain features of research area. The yellow squares represent the typical sites of North Fujian. 
Table 1. Sampling location, altitude and lengths of the Funing bay sediment cores and Neolithic sites.

\begin{tabular}{|c|c|c|c|c|c|c|}
\hline Core number or site & Sampling location & Latitude $\mathrm{N}$ & Longitude E & $\begin{array}{c}\text { Altitude } \\
(\mathrm{m})\end{array}$ & $\begin{array}{l}\text { Altitude error } \\
(\mathrm{m})\end{array}$ & $\begin{array}{c}\text { Core length } \\
(\mathrm{m})\end{array}$ \\
\hline FN1 & Muddy tidal flats near supratidal zone of Funing bay & $26^{\circ} 48^{\prime} 52.57^{\prime \prime}$ & $120^{\circ} 01^{\prime} 19.49^{\prime \prime}$ & 15 & 3 & 15 \\
\hline FN2 & Foot of Pingfeng hill & $26^{\circ} 48^{\prime} 44.26^{\prime \prime}$ & $120^{\circ} 00^{\prime} 00.80^{\prime \prime}$ & 26 & 3 & 3.4 \\
\hline Pingfengshan site & Hilltop of Pingfeng hill & $26^{\circ} 48^{\prime} 36.63^{\prime \prime}$ & $119^{\circ} 59^{\prime} 44.40^{\prime \prime}$ & 163 & 3 & - \\
\hline Huangguashan site & Hilltop of Huangguashan hill & $26^{\circ} 47^{\prime} 50.22^{\prime \prime}$ & $119^{\circ} 55^{\prime} 24.74^{\prime \prime}$ & 50 & 3 & - \\
\hline
\end{tabular}

All sample preparation was conducted under subdued red light. The middle part of sediment in each tube was pretreated with $10 \% \mathrm{HCl}$ to remove carbonates and with $\mathrm{H}_{2} \mathrm{O}_{2}$ to remove the organic matter. The $38-63 \mu \mathrm{m}$ fractions were etched with $40 \% \mathrm{HF}$ for 40 minutes to dissolve feldspars and subsequently treated with $10 \% \mathrm{HCl}$ to remove acid-soluble fluoride precipitates. The purity of the extracted quartz grains were checked using IR stimulation. The single aliquot regenerative dose (SAR) protocol (Murray and Wintle, 2000) was applied to purified medium-grained quartz (38-63 $\mu \mathrm{m})$ OSL measurement.

Samples were dated by OSL laboratory of Fujian Normal University. OSL measurements were undertaken using an automated Ris $\varnothing-T L / O S L$ DA-20C/D reader with $7.5 \mathrm{~mm}$ Hoya U-340 filters $(290-370 \mathrm{~nm})$ in front of an EMI 9235 QA photomultiplier tube. Irradiation was provided by a ${ }^{90} \mathrm{Sr} /{ }^{90} \mathrm{Y}$ beta source (Bøtter-Jensen et al., 2003). Neutron activation analysis (NAA) was employed to determining the contribution of $\mathrm{U}$, Th and $\mathrm{K}$ by China Atom Science Research Institute. The water contents are measured using the core samples after the core has been taken back to the laboratory.

In order to understand the grain-size distribution of the sediment, the sediment samples at intervals of $10 \mathrm{~cm}$ were analyzed by a Malvern Mastersizer 2000 laser parti- cle size analyzer. $30 \%$ hydrogen perocide $\left(\mathrm{H}_{2} \mathrm{O}_{2}\right)$ and $10 \%$ dilute hydrochloric acid $(\mathrm{HCl})$ were used to remove organic material and carbonates. And the samples were dissolved in $0.05 \mathrm{~mol} / \mathrm{L}$ sodium hexametaphosphate $\left(\left(\mathrm{NaPO}_{3}\right)_{6}\right)$ solution to disperse the samples, then the solutions were measured after ultrasonic desaggregation for $10 \mathrm{~s}$ on the machine.

\section{RESULTS}

\section{FN1 core stratigraphy and sediment characteristics}

The FN1 core consists of silt and sandy material. As a whole, the core can be divided into three different stratigraphic stages (Fig. 2). The uppermost $700 \mathrm{~cm}$ of sediments (unit A) are similar to neritic deposit and consists of clayey silt of grey colour (5Y4/1), silt of light grey (5Y7/1). and two $\sim 50 \mathrm{~cm}$ wide horizons at depth of $1.5 \sim 2 \mathrm{~m}$ and $2 \sim 2.5 \mathrm{~m}$ showed an obvious change in sediment colour and grain-size in contrast to adjacent sediment to thin-bedded clay of grey colour $(5 \mathrm{Y} 4 / 1)$ and medium sand of yellow colour $(2.5 \mathrm{Y} 8 / 6)$. They are connected with small steps in sea-level changes, indicated secondary transgression (high sea level) and regression (low sea level), respectively. The OSL samples PFS001 PFS007 were taken from this unit.

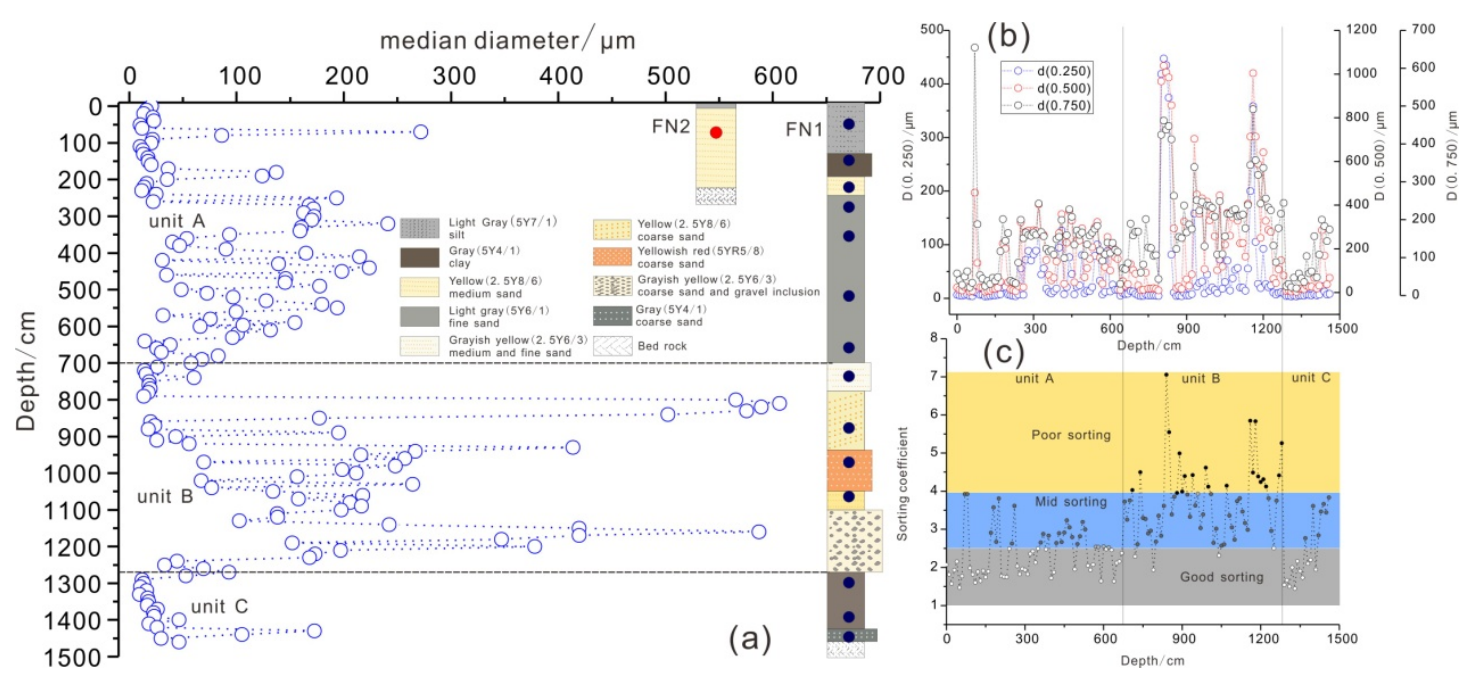

Fig. 2. Lithology and grain-size characteristics of FN1 core at Funing bay, Southeast China. And FN1 and FN2 core are located in intertidal zone and supratidal zone, respectively. (a) The distribution of median diameter with depth. The solid circles on FN1 lithology column represent the sampling location of OSL samples. (b) The distributions of different cumulative percentage composition with depth. (c) The sorting coefficient of sediment. 
The boundary between the clay silt of the uppermost unit $\mathrm{A}$ and the second unit $\mathrm{B}$ is visible at the depth of $\sim 700 \mathrm{~cm}$. Sediment composition changes abruptly and a significant step has developed in the unit B (Fig. 2a). The material is incompact and is characterized by the occurrence of various grain-size and colour sandy sediment (Fig. 2a). Specifically, the grain-size and colour of sediment (unit B), in order, are greyish yellow (2.5Y6.3) medium and fine sand, yellow $(2.5 \mathrm{Y} 8 / 6)$ coarse sand, yellowish red (5YR5/8) coarse sand, yellow (2.5Y8/6) medium sand and greyish yellow (2.5Y6/3) coarse sand and gravel inclusion. Four OSL samples (PFS008 PFS011) were taken from the sand layers in different grain-size within unit $\mathrm{B}$, respectively. There was no OSL sample obtained from the layer at depth of 1100-1270 cm because the loose stratum with coarse sand and gravel inclusion is not suitable for OSL dating, which is very likely exposed in the procedure of drilling sediment core.

The boundary to the lowest unit $\mathrm{C}$ of the FN1 core is sharp and occurs at depth of $\sim 1270 \mathrm{~cm}$ (Fig. 2a). This unit mainly consists of clay of grey colour $(5 \mathrm{Y} 4 / 1)$. In addition, coarse sand of grey colour (5Y4/1) also occurs below the clay layer. There were three OSL samples (PFS012 PFS014) were acquired from this unit.

The bed rock of granite was found about $1450 \mathrm{~cm}$ below the unit $\mathrm{C}$ at the bottom of FN1 core.

The results from grain-size analyses show that the sorting coefficient of unit $\mathrm{A}$ and $\mathrm{C}$ are good-mid sorting, and the value of unit B is poor-mid sorting (Fig. 2c). In addition, the grain-size of different accumulated percentages can also indicate the sediment phase changes in three stratigraphic units (Fig. 2a/b).

\section{Luminescence characteristics and quartz-OSL chro- nology}

Fig. 3 shows the results of preheat plateau, recycling ratios, recuperation and dose recovery for PFS005 and PFS012. For sample PFS005, the result of the preheat plateau test suggests that the dose measurement is sensitive to the preheat temperature. The $D_{\mathrm{e}}$ s slightly increased for the preheats of 240 and $280^{\circ} \mathrm{C}$. For sample PFS012, the $D_{\mathrm{e}}$ s slightly decreased for the preheats of 240 and $260^{\circ} \mathrm{C}$. Additionally, negligible thermal transfer was detected for preheat between 180 and $240^{\circ} \mathrm{C}$. Dose recovery experiment was applied to the samples with medium quartz grains that were bleached by SOL2 solar for 8 hours, and a known laboratory dose of 95.26Gy was recovered using the SAR protocol. The ratios of measured and given dose for selected sample PFS005 and PFS012 were 1.05 (preheat $220^{\circ} \mathrm{C}$ ) and 1.03 (preheat $240^{\circ} \mathrm{C}$ ) from six aliquots, respectively.

Based on the results of preheat plateau test and dose recovery test, a preheat at $220^{\circ} \mathrm{C}(10 \mathrm{~s})$ and a cut heat at $180^{\circ} \mathrm{C}(10 \mathrm{~s})$ were used for samples (PFS001-PFS008, $\mathrm{PFS} 015)$, and a preheat at $240^{\circ} \mathrm{C}(10 \mathrm{~s})$ and a cut heat at $200^{\circ} \mathrm{C}(10 \mathrm{~s})$ were selected for the rest of samples (PFS009-PFS014). Then samples were stimulated by blue light at $130^{\circ} \mathrm{C}$ for $40 \mathrm{~s}$. The first $1.6 \mathrm{~s}$ of the initial OSL signal minus a background estimated from the last $16 \mathrm{~s}$ OSL signal was used as a measurement of the last component for $D_{\mathrm{e}}$ estimation.

Fig. $4 a-4 c$ shows the decay curves of natural OSL for sample PFS001, 002 and 005. The OSL signal decreases very quickly during the first second of blue light stimulation, indicating that the decay curves are typical for quartz and seem to be predominated by the fast component (Bailey et al., 1997; Jain et al., 2003). The dose representative growth curves are shown in the Fig. $\mathbf{4 d}-\mathbf{4 f}$. The dose representative growth curves are well represented by exponential fitting with six regeneration dose points, including a zero-dose for testing recuperation and a recycling point for assessing the sensitivity change correction (Murray and Wintle, 2000). The recycling ratios are in the range of $0.9-1.1$ and the recuperation values lie below $5 \%$. These statistics suggest that the SAR protocol with medium-grained quartz can be used to establish a dependable chronology for the deposit of FN1 core. Fig. $4 \mathrm{~g}-4 \mathbf{i}$ displays the $D_{\mathrm{e}} \mathrm{s}$ distributions for three samples. Dose rate data determined by neutron activation analysis (NAA) are shown in Table 2. The histogram of $D_{\text {e }}$ distribution suggests that these samples are normally distributed which indicate the quartz grains were completed bleached by sunlight before deposition. So the central age model (CAM) of Galbraith et al. (1999) was used for age calculation and the age results of FN1 core are shown in Table 2.

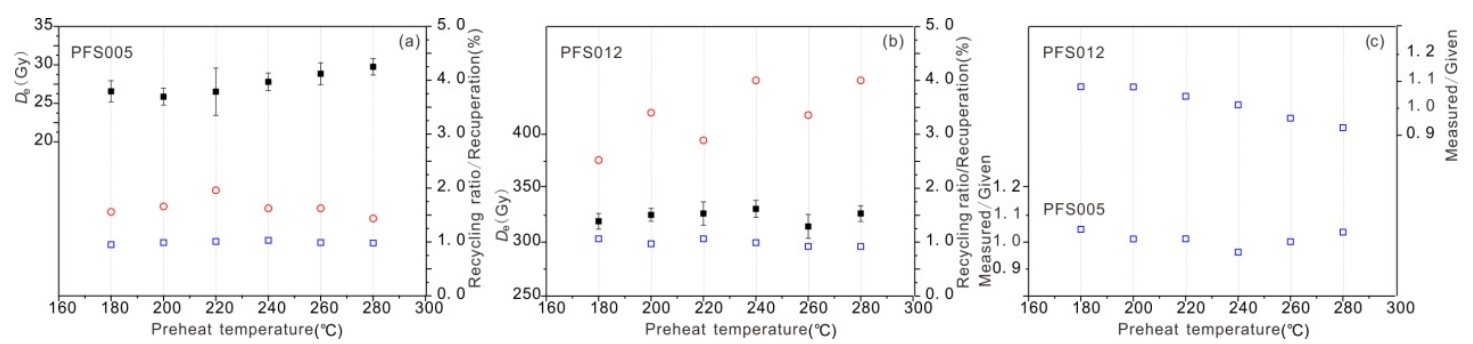

Fig. 3. Luminescence characteristics. (a) and (b). Solid squares display equivalent dose as a function of preheat temperature for the medium grained quartz for the sample PFS005 and PFS012, respectively. Open squares and circles refer to the recycling ratios and recuperation values. (c). Dose recovery test data for sample PFS005 and PFS012. 

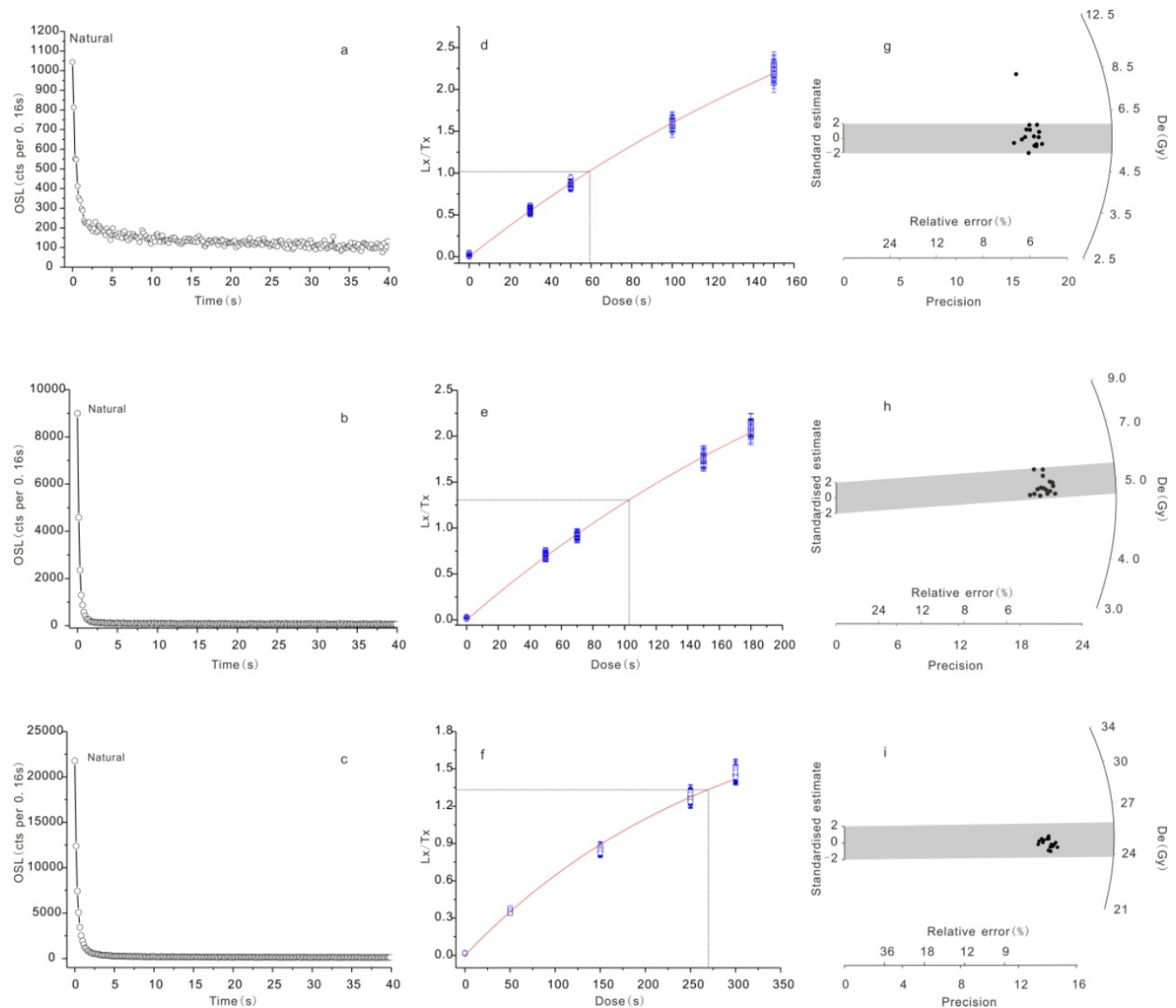

Fig. 4. Luminescence characteristics. Typical natural OSL decay curves (a-c) using the SAR procedure for mid-grained quartz of sample PFS001, PFS002 and PFS005. The OSL dose response curves $(d-f)$ are plotted from all aliquots of each sample. Radial plots showing how broad the distribution of the $D_{e}$ values of sample PFS001 (g), PFS002 (h), and PFS005 (i). The resultant $D_{e}$ value of the central age model (Table 2) is shaded.

Table 2. The OSL data of FN1 and FN2 cores at Funing bay, Southeast China.

\begin{tabular}{lccccccccc}
\hline $\begin{array}{l}\text { Sample ID } \\
\text { In lab }\end{array}$ & $\begin{array}{l}\text { Sample } \\
\text { ID }\end{array}$ & $\begin{array}{c}\mathrm{K} \\
(\%)\end{array}$ & $\begin{array}{c}\text { Th } \\
(\mathbf{p p m})\end{array}$ & $\begin{array}{c}\mathbf{U} \\
(\mathbf{p p m})\end{array}$ & $\begin{array}{c}\text { Water } \\
\text { content } \\
(\%)\end{array}$ & $\begin{array}{c}\text { Cosmic dose } \\
\text { rate } \\
(\boldsymbol{\mu G} \mathbf{G} / \mathbf{k a})\end{array}$ & $\begin{array}{c}\text { Dose Rate } \\
(\mathbf{G y} / \mathbf{k a})\end{array}$ & $\begin{array}{c}\mathbf{D}_{\mathrm{e}} \\
(\mathbf{G y})\end{array}$ & $\begin{array}{c}\text { Age } \\
(\mathbf{k a})\end{array}$ \\
\hline FNU2016027 & PFS001 & $2.58 \pm 0.07$ & $33.6 \pm 0.81$ & $8.63 \pm 0.21$ & $10 \pm 3$ & $0.179 \pm 0.022$ & $6.48 \pm 0.29$ & $5.52 \pm 0.10$ & $0.845 \pm 0.041$ \\
FNU2016028 & PFS002 & $2.58 \pm 0.07$ & $30.9 \pm 0.74$ & $10.3 \pm 0.24$ & $10 \pm 3$ & $0.151 \pm 0.012$ & $6.65 \pm 0.30$ & $5.20 \pm 0.07$ & $0.776 \pm 0.037$ \\
FNU2016030 & PFS003 & $2.94 \pm 0.07$ & $27.6 \pm 0.66$ & $7.72 \pm 0.20$ & $10 \pm 3$ & $0.134 \pm 0.010$ & $6.28 \pm 0.56$ & $5.96 \pm 0.08$ & $0.960 \pm 0.047$ \\
FNU2016029 & PFS004 & $3.65 \pm 0.08$ & $13.1 \pm 0.35$ & $2.84 \pm 0.10$ & $10 \pm 3$ & $0.121 \pm 0.023$ & $4.81 \pm 0.26$ & $9.79 \pm 0.12$ & $2.019 \pm 0.111$ \\
FNU2016031 & PFS005 & $3.30 \pm 0.08$ & $18.7 \pm 0.49$ & $6.04 \pm 0.16$ & $10 \pm 3$ & $0.107 \pm 0.016$ & $5.64 \pm 0.31$ & $25.70 \pm 0.48$ & $4.610 \pm 0.243$ \\
FNU2016032 & PFS006 & $3.42 \pm 0.08$ & $19.8 \pm 0.51$ & $5.92 \pm 0.16$ & $10 \pm 3$ & $0.086 \pm 0.006$ & $5.78 \pm 0.28$ & $27.15 \pm 1.18$ & $4.760 \pm 0.314$ \\
FNU2016033 & PFS007 & $3.56 \pm 0.08$ & $17.8 \pm 0.46$ & $4.81 \pm 0.14$ & $10 \pm 3$ & $0.070 \pm 0.005$ & $5.51 \pm 0.28$ & $34.78 \pm 0.80$ & $6.393 \pm 0.358$ \\
FNU2016034 & PFS008 & $3.31 \pm 0.08$ & $18.6 \pm 0.48$ & $5.02 \pm 0.15$ & $10 \pm 3$ & $0.064 \pm 0.005$ & $5.38 \pm 0.27$ & $67.24 \pm 0.27$ & $12.666 \pm 0.69$ \\
FNU2016035 & PFS009 & $3.25 \pm 0.07$ & $23.9 \pm 0.60$ & $6.50 \pm 0.23$ & $10 \pm 3$ & $0.054 \pm 0.004$ & $5.98 \pm 0.29$ & $162.35 \pm 4.92$ & $27.466 \pm 1.58$ \\
FNU2016036 & PFS010 & $3.56 \pm 0.08$ & $15.4 \pm 0.40$ & $4.07 \pm 0.13$ & $10 \pm 3$ & $0.049 \pm 0.004$ & $5.16 \pm 0.27$ & $144.18 \pm 10.15$ & $28.259 \pm 2.48$ \\
FNU2016037 & PFS011 & $3.86 \pm 0.08$ & $21.20 \pm 0.53$ & $6.480 \pm 0.17$ & $10 \pm 3$ & $0.044 \pm 0.004$ & $6.27 \pm 0.31$ & $140.05 \pm 4.07$ & $22.345 \pm 1.29$ \\
FNU2016038 & PFS012 & $2.77 \pm 0.07$ & $26.00 \pm 0.62$ & $7.910 \pm 0.20$ & $10 \pm 3$ & $0.035 \pm 0.002$ & $5.91 \pm 0.28$ & $324.17 \pm 28.66$ & $54.854 \pm 5.50$ \\
FNU2016039 & PFS013 & $3.38 \pm 0.08$ & $25.90 \pm 0.62$ & $8.320 \pm 0.20$ & $10 \pm 3$ & $0.032 \pm 0.003$ & $6.53 \pm 0.31$ & $271.92 \pm 16.75$ & $41.617 \pm 3.25$ \\
FNU2016040 & PFS014 & $3.73 \pm 0.08$ & $24.30 \pm 0.61$ & $5.850 \pm 0.16$ & $10 \pm 3$ & $0.031 \pm 0.002$ & $6.20 \pm 0.31$ & $309.22 \pm 18.04$ & $49.892 \pm 3.83$ \\
FNU2016041 & PFS015 & $3.57 \pm 0.08$ & $23.00 \pm 0.58$ & $5.570 \pm 0.16$ & $10 \pm 3$ & $0.176 \pm 0.148$ & $6.06 \pm 0.33$ & $45.60 \pm 1.260$ & $7.530 \pm 0.46$ \\
\hline
\end{tabular}




\section{DISCUSSION}

\section{Reliability of quartz-OSL ages}

As what mentioned before, the laboratory parameters such as preheat, recycling ratios and recuperation of medium-quartz indicate that those OSL signals are fit for $D_{\mathrm{e}}$ determination (Long and Shen, 2015; Jin et al., 2017a). According to the relationship between OSL age and depth for the FN1 core, it can be seen that the 14 OSL ages show a well consistency with sequences universally yielding ages in stratigraphic succession. Moreover, in order to further verify the reliability of quartz-OSL ages in this area, 4 OSL samples were collected from the cultural layers of Pingfengshan site. The results of ages comparison are shown in Table 3 and Fig. 5. The comparison of OSL and AMS ${ }^{14} \mathrm{C}$ dating of the layers from Pingfengshan site suggests that the two dating technique agree well for the Holocene samples (Fig. 5). Considering of the depositional characteristics of slop wash and measurement accuracy of OSL technology, we think that the OSL data are reliable.

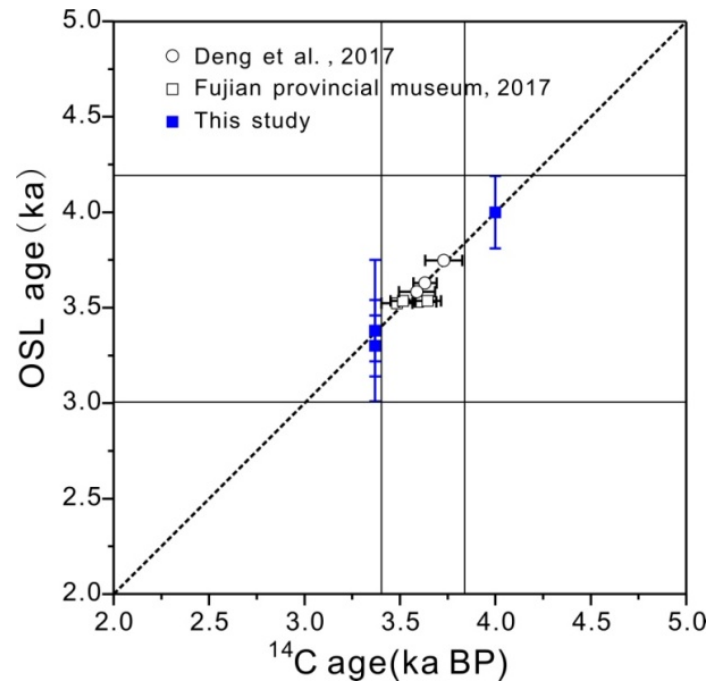

Fig. 5. Ages comparison.

\section{Evolution of the FN1 depositional environment}

The ages and grain-size results identify three distinct environmental units in the transformation of the Funing bay and the coastal area of north Fujian (Fig. 6a). Meanwhile, the sketch maps of shoreline change of research area at several typical given times are shown in Fig. 7. We interpret the finding by comparison with the results of previous palaeoenvironmental studies (eg. Zeng, 1991; Lambeck et al., 2002; Lea et al., 2002; Jin et al., 2017a).

The earliest stage is roughly corresponding to marine oxygen isotope (MIS) stage 3 . The duration of the unit $\mathrm{C}$ formation is approximately equal to $60-40 \mathrm{ka}$ from now based on laboratory test results. The mean relative sea level of MIS 3 was about $-55 \mathrm{~m}$ above sea level (a.s.l) (Kenneth et al., 2005). In some places the relative sea level maintained at $-80 \mathrm{~m}$ a.s.l (Yokoyama et al., 2000). The clay deposition with thin-bedded coarse sand indicated a neritic and tidal flat facies. Recent research has shown that the climate condition was unstable and several abrupt changes of climate were occurred in this stage. The coastline and the submarine topography were under an accelerated evolution by this quick changing of climate. The sediment of this stage is very likely discontinuous under the influence of complicated hydrodynamic environment. So, the OSL data of this core (unit C) manifest as stratigraphic inversion. The grain-size characteristics of this unit show well sorted and fine particle with a large number organic substance, indicating a stable and relatively weak hydrodynamic environment. There were old coastal aeolian sand, shown in red or brown colour, distributed in Fuzhou basin and coastal area of Fujian in this period according to the newest investigate (Jin et al., 2017b). This suggests that the environment of research area, closer to coastline, should be neritic environment. In the region-wide view, the sedimentary records of MIS 3 are widely distributed and well preserved in China's coastal plains, Huanghai and Bohai sea and the East China Sea as well (Zhang et al., 2010). Therefore, the OSL dating results of FN1 core (unit C) provide a new chronological evidence on the transgression of MIS 3.

Table 3. $A M S{ }^{14} \mathrm{C}$ and $O S L$ dating results from Pingfengshan site.

\begin{tabular}{|c|c|c|c|c|c|}
\hline Site & Laboratory code & Context NO. & Sample type & 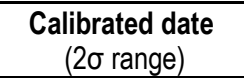 & Reference \\
\hline \multirow{11}{*}{ Pingfengshan } & Beta-434875 & Layer 3 & charcoal & 3565-3403 cal. BP & \multirow{4}{*}{ Fujian Provincial Museum, 2017} \\
\hline & Beta-434876 & Layer 4 & charcoal & 3691-3495 cal. BP & \\
\hline & Beta-434877 & Layer 5 & charcoal & $3582-3450$ cal. BP & \\
\hline & Beta-434878 & Layer 5 & charcoal & 3716-3572 cal. BP & \\
\hline & UGAMS\#27094 & Layer 3 & rice & 3692-3570 cal. BP & \multirow{3}{*}{ Deng et al.,2017 } \\
\hline & UGAMS\#27093 & Layer 4 & rice & 3684-3494 cal. BP & \\
\hline & UGAMS\#27092 & Layer 5 & rice & 3826-3632 cal. BP & \\
\hline & $\overline{\text { FNU2016003 }}$ & Layer 4 & quartz & $3.38 \pm 0.37 \mathrm{ka}$ & \multirow{4}{*}{ This study } \\
\hline & FNU2016004 & Layer 5 & quartz & $4.00 \pm 0.19 \mathrm{ka}$ & \\
\hline & FNU2016008 & Layer 4 & quartz & $3.38 \pm 0.16 \mathrm{ka}$ & \\
\hline & FNU2016009 & Layer 4 & quartz & $3.30 \pm 0.16 \mathrm{ka}$ & \\
\hline
\end{tabular}


The deposition process of the second stage mainly occured in the MIS3/2 transition and MIS 2. It is mainly continental deposit (in particular, fluvial alluvial and proluvial facies, a small part of aeolian sand deposit) based on the chromaticity and granularity of FN1 core (unit B). This sedimentary facies occur in response to the rapid falling of sea level following the relative thalassocratic period of MIS 3. In some tectonically stable areas or neighbouring regions where the tectonic rate is known and has been removed from the observed signal, a similar phenomenon can be observed (Wang et al., 1981; Bard, 1998; Hanebuth et al., 2000; Yokoyama et al., 2000; Liu et al., 2015). It would be specially mentioned that the sorting coefficient and cumulative relative frequency curves of horizon at depth 10-11 m are much closer to the features of aeolian sand deposit. The aeolian sand is usually eroded or there was no aeolian sand has deposited at that time, because this area is located beyond the coastal crust about a few tens of kilometres (Jin et al., 2017b). Only part of aeolian sand residues has been saved in the former fluvial plain. The sedimentary environment of this period in research area, in this sense, has been influenced by wind, which conformed with the cold and dry climate records of the Last Glaciation Maximum (LGM).

The uppermost $700 \mathrm{~cm}$ of sediments (unit A), which are mainly corresponding to mid-late Holocene (MIS 1), represents the final stage in the evolution of the FN1 core depositional environment. The transition to unit A is characterized by steep increase in fine grained content and a steep decline in coarse grained content, coupled with a good-mid sorting and light grey colour. Seven OSL data are $6.393 \pm 0.358 \mathrm{ka}, 4.76 \pm 0.314 \mathrm{ka}$, $4.61 \pm 0.243 \mathrm{ka}, 2.019 \pm 0.111 \mathrm{ka}, 0.960 \pm 0.047 \mathrm{ka}$, $0.776 \pm 0.037 \mathrm{ka}$ and $0.845 \pm 0.041 \mathrm{ka}$, respectively. The clay and silt deposit represent a neritic environment, which conform to the result of high sea-level in this period. It has been proved that three thalassocratic stages have raced at coastal area of Fujian since about $7 \mathrm{ka}$, and the highest sea level was usually less than $4 \mathrm{~m}$ a.s.l compared with nowadays (Wang et al., 1994; Zeng, 1991, 1997), although the time highest sea level of each thalassocratic stages happened is still controversial (Ma et al., 2016). In general, the deposition of FN1 core reflects the process of transgression and regression of coastal area of Fujian since MIS 3 to MIS 1.

\section{Holocene sea-level history of northeast Fujian and Neolithic cultural response}

As noted above, there is still significant uncertainty over the timing, magnitude and variability of the Holocene highstand in coastal area of Fujian (the west coast of the Taiwan Straits) (Wang et al., 1994; Zeng, 1991), and it is also includes the rate of sea level change (e.g. Ma et al., 2016; Bird et al., 2007; Zong, 2004; Zeng, 1991). Some sea level curves (Lea et al., 2002; Wang et al., 1994; Zeng, 1991) sets are shown in Fig. 5a/b, which also incorporates new OSL data from the FN1 sediment core. Fig. 6 shows sea level curves for globe (Fig. 6a) and the north east coastal area of Fujian (Fig. 6b), which are based on planktonic $\mathrm{Mg} / \mathrm{Ca}$ and oxygen isotope records and the radiocarbon data from six types of sea level indicators, respectively.

The deposit of unit A (FN1 core) represents the Holocene sea level history. Of particular interest is the clayey silt deposit near the base of unit A stratigraphic sequence ( $\sim 6.7 \mathrm{~m}$ below surface). This layer dated about $6.4 \mathrm{ka}$ likely accumulated along the shoreline during the marine transgression, which corresponds to a large scale transgressive event deposition named "Changle transgression" by Lin (1979). Thus, this result marks the intertidal zone during the Mid Holocene "Changle transgression" of Funing bay. A simple estimation of relative sea level for this index layer, using the present elevation above sea level minus the depth and the tidal data, suggests that it was $2.78 \mathrm{~m}$. It provides a useful approximation for contrast with sea level change from other studies. This estimate of $2.78 \mathrm{~m}$ at $6.4 \mathrm{ka}$ is roughly consistent with data form Zeng (1991), which measures relative sea level at $6.1 \mathrm{ka}$ at $3 \mathrm{~m}$. So the lower deposits of unit A provides another sea level indicator.

A transition period between the yellow medium sand layer at $2-2.5 \mathrm{~m}$ and the light grey fine sand layer at 2.5-7 $\mathrm{m}$ provides an obvious transgression-regression cycle dated to $0.96 \mathrm{ka}(\sim 2.2 \mathrm{~m})$ and $2.0 \mathrm{ka}(\sim 2.9 \mathrm{~m})$, respectively. Funing bay used to be a ship-building base of the ancient Wenma County which is part of kingdom of $\mathrm{Wu}$ in the Period of Three Kingdoms (220-280 AD). A boat was discovered in the foot of Pingfengshan hill and dated 75 to $235 \mathrm{AD}$ under 2 sigma calibration based on AMS radiocarbon dating (Fujian provincial museum, 2017). It can provide evidence that there was a period of sea level rising. That is, there was enough water to float the boat as an ancient port. The discard of ship-building base was very likely related to the change of sea level of the time.

Why there were no sites older than $4.3 \mathrm{ka}$ cal BP discovered in research area so far? It is extremely likely that sea-level fluctuations played an important role in human activities and migrations since about $7 \mathrm{ka}$ (Chen et al., 2015). Fig. 6b shows the relationship between sea level change and ancient cultures since about $7 \mathrm{ka}$. As a whole, the ancient cultures of Fujian correspond directly to three periods of sea level rising since about $7 \mathrm{ka}$. As shown in Fig. 6b, Keqiutou culture (age range is about 6-5.5 ka cal BP) is the earliest Neolithic culture in coastal Fujian. One characteristic of this culture is most sites on offshore islands. And the typical sites are distributed mainly over Pingtan Island about $120 \mathrm{~km}$ from Fuzhou Basin. This period is just at the highest sea level of Holocene in coastal Fujian, ancient people of here compelled to immigrate to inland westward or offshore island southward because of the rising sea level. So, fishing and hunting might be the main economy (Fujian provincial museum, 


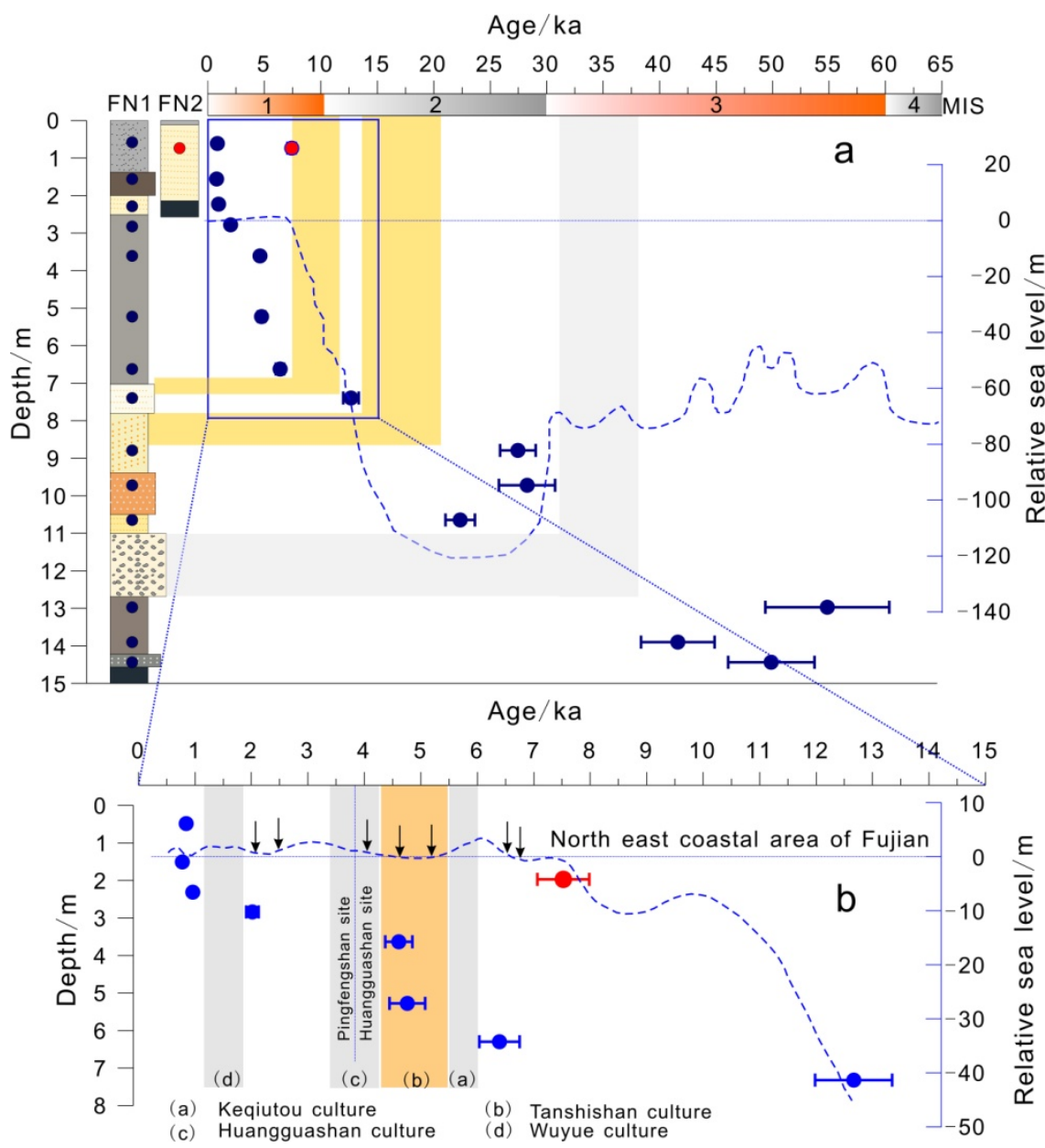

Fig. 6. The chronology of FN1 core and compared with fluctuation of sea level. The dash lines in $6 a$ and $6 b$ represent the global sea level change (Lambeck et al., 2002) and the sea level change of North Fujian (Zeng, 1991), respectively. The red cycle in $6 b$ represents the age of corn FN2.

$\stackrel{0}{1}$

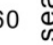

80

$00 \stackrel{\bar{\Phi}}{\check{\Upsilon}}$

20

1991). Tanshishan culture (age range is about 5-4.3 ka cal BP) characterized by low intensity agriculture is a maritime culture cantered on Fuzhou Basin and the midHolocene Min River estuary (Rolett et al., 2011). We should note that these sites of Tanshishan culture period (5-4.3 ka cal BP) mainly located on the estuarine islands or lower terraces of Min River and the elevation is not more than $10 \mathrm{~m}$ a.s.l (Lin, 2012). It is indicated that the sites of Tanshishan Lower-layer culture period (5.5-5 ka cal BP) should located in the place where the elevation were lower than that of Tanshishan culture sites (5-4.3 ka cal BP). There are not enough sites to distinguish Tanshishan Lower-layer culture (5.5-5 ka cal BP) from Tanshishan culture (5-4.3 ka cal BP) at present. This inference is likely to lead us to find more sites of Tanshishan Lower-layer culture period (5.5-5 ka cal BP).

Of flourish ancient culture of research area is Huangguashan culture (age range is about $4.3-3.5 \mathrm{ka}$ cal BP). This period characterized by low intensity agriculture and agricultural activities might be the supplement of maritime economy base on the analysis of excavated datum (Fujian provincial museum, 2017). As far as time alignment is concerned, the lifespan of Pingfengshan site (3.8-3.5 ka cal BP) is later than that of Huanggaushan site (4.3-3.8 ka cal BP). This appearance precisely corresponds to the process of sea level rising from $4.3 \mathrm{ka}$ to $3.5 \mathrm{ka}$ (Fig. 6b). The rising sea level can reasonably answer the scientific question that why the sites of early stage of Huangguashan culture period (e.g. Huangguashan site at an altitude of $50 \mathrm{~m}$ a.s.l) were moved farther to higher than that of later stage of Huanguashan culture period (eg. Pingfengshan site at an altitude of $163 \mathrm{~m}$ a.s.l).

Numerous studies have now shown that there was a period of higher sea level at about 2.0-1.5 ka before present (Zeng, 1997; Lin, 2012; Ma et al., 2016). The radiocarbon dating result ( 75 to $235 \mathrm{AD}$ ) of the unearthed boat can be used as important evidence for higher sea level of the time. As one of the three ship building bases of ancient kingdom of $\mathrm{Wu}$, one of the basic prerequisites should be keep extra depth to ensure navigation safety. The shipyard was deprecated when the sea level restored gradually to current state and continual war (Ge, 2011) after 1.5 ka before present. 

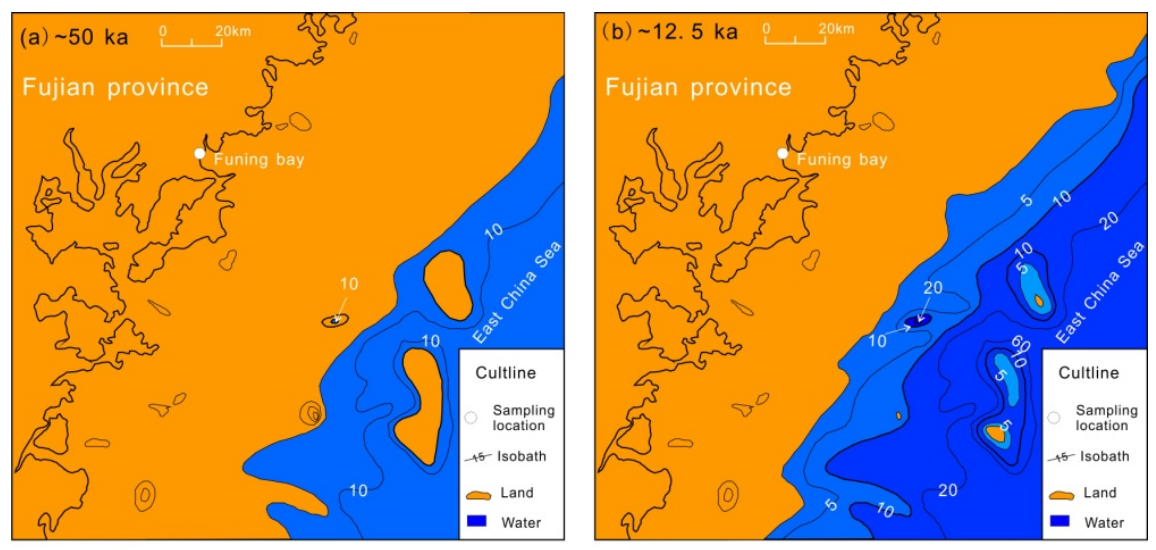

Fig. 7. Sketch map of shoreline change of northeast coastal area of Fujian province, China at different stages.
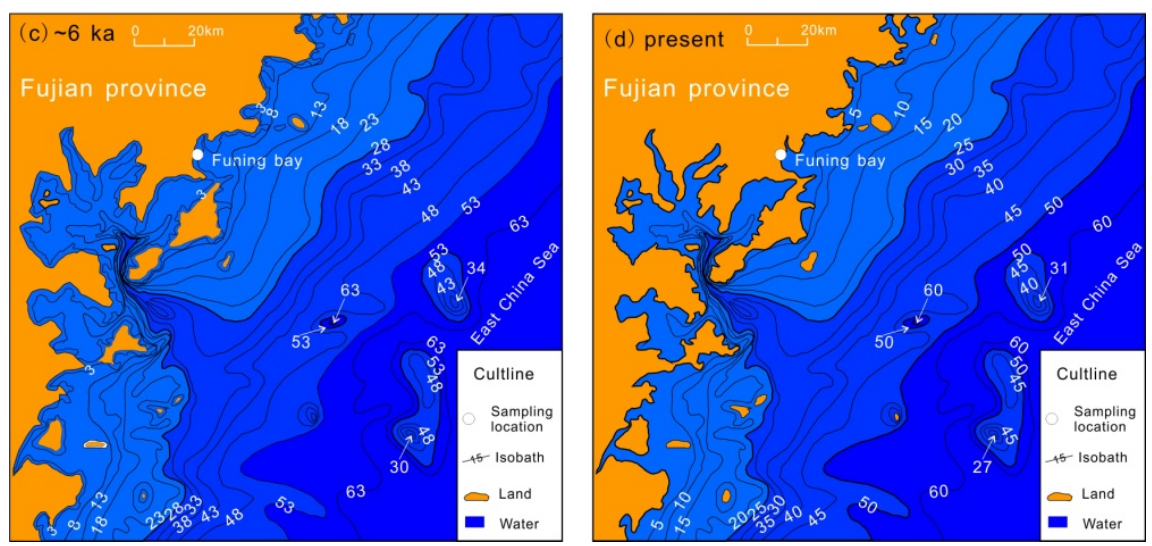

\section{CONCLUSIONS}

The human-environment interactions in coastal area of South China are still controversial because of the scarcity of a reliable and systematic chronology of both deposit sediments and archaeological sites. In this study, we presented the OSL ages obtained from the mediumgrained quartz of FN1 core and Pingfengshan site at the Funing bay along the coastal of Fujian province, China. SAR measurements of archaeological site (Pingfengshan site) yielded internally and stratigraphically consistent ages within errors, indicating competent reliability of the technique verified with AMS ${ }^{14} \mathrm{C}$ technique. The results showed that the ages of FN1 core deposit were varied from $50 \pm 4 \mathrm{ka}$ to $0.8 \pm 0.04 \mathrm{ka}$. The deposit periods linked to MIS $3 \mathrm{c} / \mathrm{b}$, MIS $3 / 2$ and MIS 1 , respectively. And there is a visible break between MIS 2 and MIS 1 . The core has a continuous sediment record from around 7 ka until the present. This time period spans the entire Neolithic era of the Fujian archaeological sequence. Based on the direct correspondence between sea level change and different Neolitic culture periods, we deduce that the cultural types of Keqiutou culture and Huangguashan culture all belong to coastal mountainous culture, of which flourishing periods corresponds to the higher sea level periods of mid-late Holocene.
Tanshishan culture belongs to estuarine coastal culture, and most sites of this period correspond to a lower sea level period located at lower altitudes. However, at present we could not establish a precise correspondence between sea level change and human dispersal, due to the scarcity of chronology. More dating work is required, and accurate chronologies for Neolithic sites and coastal deposit cores will be the research focus in our further work.

Besides, what deserve attention especially is that the sample pretreatment and grain size component are important for us to make a correct assessment of the grain size of grains being measured and the corresponding dose rate component (Armitage and Bailey, 2005). And the water contents are also important for calculating the dose rates. Paying more attention to those influence factors is required in future work.

\section{ACKNOWLEDGEMENTS}

We especially thank anonymous reviewers whose comments greatly improved this paper. This work was supported by the National Natural Science Foundation of China (Grants 41301012, 41771020), Key Scientific and Technological Project of Fujian Province (Grant 2018R1034-5) and Innovation Research Team Found of Fujian Normal University (Grant IRTL1705). 


\section{REFERENCES}

Aitken MJ, 1998. An introduction to optical dating. Oxford University Press, New York.

Armitage SJ and Bailey RM, 2005. The measured dependence of laboratory beta dose rates on sample grain size. Radiation Measurements 39(2): 123-127, DOI 10.1016/j.radmeas.2004.06.008.

Bailey RM, Smith BW and Rhodes EJ, 1997. Partial bleaching and the decay form characteristics of quartz OSL. Radiation Measurements 27(2): 123-136, DOI 10.1016/S1350-4487(96)00157-6.

Bailey GN and Flemming NC, 2008. Archaeology of the continental shelf: marine resources, submerged landscapes and underwater archaeology. Quaternary Science Reviews 27(23-24): 2153-2165, DOI 10.1016/j.quascirev.2008.08.012.

Bard E, 1998. Radiocarbon calibration by means of mass spectrometric $230 \mathrm{Th} / 234 \mathrm{U}$ and $14 \mathrm{C}$ ages of corals: an updated database including samples from Barbados, Mururoa and Tahiti. Radiocarbon 40(3): 1085-1092.

Bird MI, Fifield LK, Teh TS, Chang CH, Shirlaw N and Lambeck K, 2007. An inflection in the rate of early mid-Holocene eustatic sealevel rise: A new sea-level curve from Singapore. Estuarine Coastal \& Shelf Science 71(3): 523-536, DOI 10.1016/j.ecss.2006.07.004.

Bøtter-Jensen L, Andersen CE, Duller GAT and Murray AS, 2003. Developments in radiation, stimulation and observation facilities in luminescence measurements. Radiation Measurements 37(4): 535-541, DOI 10.1016/S1350-4487(03)00020-9.

Chen Z, Liu Y, Chen J and Sun, Q, 2015. The key issues of Holocene sea-level study of mega-deltas: examples from the Changjiang river, the Nile river and the Mississippi river. Quaternary Sciences 35(2): 275-280.

Deng Z, Hung H-C, Fan X, Huang Y and Lu H, 2017. The ancient dispersal of millets in southern China: New archaeological evidence. The Holocene 28(1): 34-43, DOI 10.1177/0959683617714603.

Fan XC, Cheng L and Liu GJ, 2014. The Anshan sand dunes archaeological sites of Bronze Age in Jinjiang, Fujian. Cultural Relic 2: 416. (in Chinese)

Fujian Provincial Museum, 1991. Brief report of the ecavation of the Keqiutou site in Pingtan county, Fujian. Kaogu 199: 587-599. (in Chinese)

Fujian Provincial Museum, 2017. A brief introduction of Excavation at the Pingfengshan site in Xiapu county Fujian province. Fujian wenbo 1: 1-8. (in Chinese)

Galbraith RF, Roberts RG, Laslett GM, Yoshida H and Olley JM, 1999. Optical dating of single and multiple grains of quartz from jinmium rock shelter, northern Australia: part I, Experimental design and statistical models. Archaeometry 41(2): 339-364, DOI 10.1111/j.1475-4754.1999.tb00987.x.

Ge QS, 2011. Climate change of different dynasties in China. Science Press, Beijing. (in Chinese)

Hanebuth T, Stattegger K and Grootes PM, 2000. Rapid flooding of the Sunda Shelf: A late-glacial sea-level record. Science 288(5468): 1033, DOI 10.1126/science.288.5468.1033.

Jain M, Murray AS, Bøtter-Jensen L, 2003. Characterisation of bluelight stimulated luminescence components in different quartz samples: implications for dose measurement. Radiation Measurements 37(4-5): 441-449, DOI 10.1016/S1350-4487(03)00052-0.

Jin JH, Li ZZ, Huang YM, Jiang F, Fan XC, Ling ZY, Cheng Y and Xu XL, 2017a. Chronology of a late Neolithic Age site near the southern coastal region of Fujian, China. The Holocene 27(9): 12651272, DOI 10.1177/0959683616687383.

Jin JH, Li ZZ, Lei GL, Ling ZY, Jiang F, Shen JL, Liu XM, 2017 b. Chronology and Environmental Significance of Old Red Sand in South China: Take the Old Red Sand in Qingfeng, Fujian as An Example. Scientia Geographica Sinica 36(2): 301-310.

Kenneth GM, Michelle AK, James VB, James DW, Gregory SM, Miriam EK, Peter JS, Benjamin SC, Nicholas C-B and Stephen
FP, 2005. The Phanerozoic record of global sea-level change. Science 310(5752): 1293-1298, DOI 10.1126/science.1116412.

Lambeck K, Yokoyama Y and Purcell T, 2002. Into and out of the last glacial maximum: sea-level change during oxygen isotope stages 3 and 2. Quaternary Science Reviews 21(1): 343-360, DOI 10.1016/S0277-3791(01)00071-3.

Lea DW, Martin PA, Pak DK and Spero HJ, 2002. Reconstructing a 350 ky history of sea level using planktonic $\mathrm{Mg} / \mathrm{Ca}$ and oxygen isotope records from a Cocos Ridge core. Quaternary Science Reviews 21(1): 283-293, DOI 10.1016/S0277-3791(01)00081-6.

Lin G, 2012. Prehistoric archaeology and early marine culture of coastal region of Fujian. Fujian wenbo 1: 46-50. (in Chinese)

Lin JX, 1979. Preliminary notes on Holocene transgression in the seaboard of Fujian, South China. Chinese Science Bulletin 24(11): $517-520$.

Liu S, Feng A, Li P, Du J, Li P and Gao W, 2015. High-resolution grain size distribution and evolution of the sediment-dynamic environment in the modern yellow river delta since latest pleistocene. Quaternary Sciences 35(2): 320-326.

Long H and Shen J, 2015. Underestimated $\sim(14) C$-based chronology of late Pleistocene high lake-level events over the Tibetan Plateau and adjacent areas: Evidence from the Qaidam Basin and Tengger Desert. Science China Earth Sciences 58(2): 183-194, DOI 10.1007/s11430-014-4993-2.

Ma M, Ge W, Li C, Xing H, Hu S, Liu X and Zhou G, 2016. Magnetic responses to sea-level fluctuations since about 7800a B.P. recorded by core sediments at Xiapu, Fujian. Quaternary Sciences 36(5): $1307-1318$

Murray AS and Wintle AG, 2000. Luminescence dating of quartz using an improved single-aliquot regenerative-dose protocol. Radiation Measurements 32(1): 57-73, DOI 10.1016/S1350-4487(99)00253$\mathrm{X}$.

Nian X, Chen F, Li F and Gao X, 2015. Optical dating of a Paleolithic site near the eastern coastal region of Shandong, northern China. Quaternary Geochronology 30: 466-471, DOI 10.1016/j.quageo.2015.02.009.

Rolett BV, Zheng Z and Yue Y, 2011. Holocene sea-level change and the emergence of Neolithic seafaring in the Fuzhou Basin (Fujian, China). Quaternary Science Reviews 30(7-8): 788-797, DOI 10.1016/j.quascirev.2011.01.015.

Wang PX, Min QB, Bian YH and Cheng XY, 1981. Strata of quaternary transgressions in east China: a prelinimary study. Acta Geological Sinica 55(1): 1-13.

Wang S, Yang J, Zeng C, Wu X and Yu M, 1994. Sea level changes since late Pleistocene along Fujian coast. Journal of Oceanography in Taiwan Strait 13(2): 156-175.

Wintle AG and Murray AS, 2006. A review of quartz optically stimulated luminescence characteristics and their relevance in singlealiquot regeneration dating protocols. Radiation Measurements 41(4): 369-391, DOI 10.1016/j.radmeas.2005.11.001.

Yokoyama Y, Lambeck K, De DP, Johnston P and Fifield LK, 2000. Timing of the last glacial maximum from observed sea-level minima. Nature 406(6797): 713, DOI 10.1038/35021035.

Zhang J, Tsukamoto S, Grube A and Frechen M, 2014. OSL and 14C chronologies of a Holocene sedimentary record (Garding2 core) from the German North Sea coast. Boreas 43(4): 856-868, DOI 10.1111/bor.12071.

Zhang ZK, Xie L, Zhang YF, Xu J, Li SH and Wang Y, 2010. Sedimentary records of the mis 3 transgression event in the north Jiangsu plain, China. Quaternary Sciences 30(5): 883-891.

Zeng CS, 1991. Sea level variation along Fujian Coast in Holocene. Journal of Oceanography in Taiwan Strait 10(1): 77-84.

Zeng CS, 1997. Transgressions and sea level changes along the northeast coast of Fujian during the late Quaternary. Journal of Fujian Normal University (Natural Science) 13(4): 94-101.

Zong Y, 2004. Mid-holocene sea-level highstand along the southeast coast of China. Quaternary International 117(1): 55-67, DOI 10.1016/S1040-6182(03)00116-2. 